${ }^{5}$ Ver, especialmente, Marcos Cueto (org.), Missionaries of science: the Rockefeller Foundation and Latin America, Bloomington, Indiana, Indiana University Press, 1994; e, do mesmo autor, 'Sanitation from above: yellow fever and foreign intervention in Peru, 1919-1921', Hispanic American Historical Review, 72, 1: 1-22, 1992.

${ }^{6}$ Uma versão cleste artigo em língua inglesa encontra-se em Cueto (org.), 'Visions of science and development. the Rockefeller Foundation's Latin American surveys of the 1920's', Missionaries of Science, pp.1-22.

7 Dados de Steven Williams, 'Nationalism and public health: the convergence of Rockefeller Foundation technıques and Brazilian fecteral authorty during the timeof yellow fever, 1925-1930', em Cueto (org.), Missionaries of science, pp. 23-51.

${ }^{8}$ Chalhoub publıcou o capítulo sobre febre amarela em inglês; ver 'The politics of disease control yellow fever and race in nineteenth century Rio de Janeiro', J. Lat. Amer. Stud., 25: 441-63, 1993.

\title{
Enciclopédia das raças brasileiras
}

\author{
Encyclopedia of brazilian races
}

\author{
Rober to Motta \\ Professor de antroplogia da Universidade \\ Federal de Pernambuco \\ Rua Santos Elias, 104/708 \\ 52020-090 Recife - Pe
}

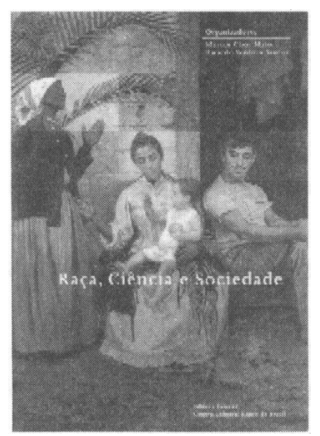

Marcos Chor Maro e Ricarclo Ventura Santos (orgs )

Raça, Ciêncta e

Soctedade

Editora Fiocruz, 1996 PP 252
S e compreendermos antropologia justamente como o estudo de raça, $\mathcal{O}$ ciência e socieclade, a antropologia brasileira o que, apesar do que possam dizer teóricos de várias orientações, teria como marco inicial certo artigo do naturalista alemão Karl von Martius, publicado em 1845 no Jornal do Instituto Histórico e Geográfico Brasileiro, "no qual argumentava que, para se escrever a história do Brasil, era premente abordar as características das três raças que o compunham" (p. 9). Para o estudo desse e de outros marcos iniciais está voltado o artigo que abre o livro em questão, a cargo de John Manuel Monteiro, 'As raças inclígenas no pensamento brasileiro do Império' (pp. 15-22). Destaquemos a atuação de João Baptista de Lacerda Filho (1882, pp. 6-7, 20), várias vezes mencionado neste artigo e no de Giralcla Seyferth, ainda que nenhum antropólogo brasileiro da atualidade, nem sequer os do Museu Nacional, no qual trabalhou, o reivindicasse como antepassado intelectual. Através de muitas medições de crânios e índices do mesmo naipe, Lacerda chegaria à conclusão de que "o nosso indígena, mesmo civilizado, não poderia produzir a mesma quantidade de trabalho útil, no mesmo tempo que os indivíduos de outras raças, especialmente da raça negra... . Eis aí como de um problema antropológico deduz-se um problema econômico e inclustrial." Apesar da falta de progênie reconhecida deste ilustre pesquisador, muitos laivos de sua teoria vão ser encontrados em Gilberto Freyre e noutros autores de nossas ciências sociais, mais africanófilos que indianófilos.

Não poderia faltar em coletânia patrocinada pela Casa de Oswaldo Cruz (COC) o artigo 'Condenado pela raça, absolvido pela medicina: o Brasil descoberto pelo movimento sanitarista da primeira República' (pp. 23-40), redigido por Nísia Trindade Lima e Gilberto Hochman. A frase conhecida por todo adolescente da década de 1950 - "O Brasil é um imenso hospital" — foi 
primeiro pronunciada, conforme esclarecem os autores, por Miguel Pereira, professor da Faculdade de Medicina do Rio de Janeiro. Passando pelo ufanismo do Conde de Afonso Celso, "que trazia com mais força um novo elemento: a valorização das três raças" (p. 27), e pelas versões pessimista e otimista do Jeca Tatu, de Monteiro Lobato, os autores concluem que " A identificação da doença como o principal problema do país não o condenava à barbárie eterna, mas, ao contrário, apontava os instrumentos para sua superação: a ciência médica e as políticas públicas de saúde e saneamento" (p. 37).

O já mencionado artigo de Giralda Seyferth ostenta um título que bem poderia ser uma tese por direito próprio: 'Construindo a nação: hierarquias raciais e o papel do racismo na política de imigração e colonização' (pp. 4158). Omitindo suas muitas informações, passemos diretamente à conclusão: "Os cientistas brasileiros encontraram meios para contornar a visão negativa sugerida pelo racismo para a mistura de raças ... inventaram a tese do branqueamento e os mestiços 'superiores'!" (p. 49). E, "nesta perspectiva, interessam principalmente os assimiláveis latinos - portugueses, italianos, franceses e espanhóis (e os 'produtivos' alemães são inconvenientes por sua irredutibilidade étnica) e os que têm melhor desempenho na atividade agrícola e artesanal". ...Quanto aos africanos, sequer foram cogitados como imigrantes" (pp. 53, 56-7).

$\mathrm{O}$ artigo seguinte, de Jair de Souza Ramos, intitulado 'Dos males que vêm com o sangue: as representações raciais e a categoria do imigrante indesejável nas concepções sobre a imigração da década de 20' (pp. 5982 ), versa sobre o projeto de um grupo de negros norte-americanos de organizar uma companhia de colonização no Mato Grosso em 1921. Apesar dos detalhes de interesse histórico, a conclusão não surpreende: "Os mecanismos de seleção de imigrantes tiveram ... papel de reforço e reprodução da hierarquia entre populações, característica da sociedade brasileira, dos não-brancos. ... Tratava-se, sobretudo, de esconjurar o risco máximo de não brancos indóceis, inassimiláveis e que pusessem em questão a hierarquia racial - o que era o caso da representação que recaía sobre os afro-americanos" (p. 81).

Assim chegamos à segunda parte do livro, voltada para 'A reinvenção da raça nas décadas de 30 e 40'. Omar Ribeiro Thomaz, abre a seção tratando 'Do saber colonial ao luso-tropicalismo: raça e nação nas primeiras décadas do salazarismo' (pp. 85-106). Vejamos com mais rapidez do que o assunto estaria a merecer algumas das teses desse "saber": "Os navegadores e conquistadores lusitanos, fascinados e assombrados com terras e gentes exóticas, com a fauna e a flora dos territórios tropicais, e sentindo a necessidade imperiosa de compreender e relatar aos que ficavam as preciosidades encontradas, desenvolveram 'o espírito de obsrvação, o espírito científico." Estavam imbuídos de "uma noção de civilização que ... significava exportar ciência a povos que ainda permaneciam no obscurantismo da vida tribal e em um cotidiano permeado por elementos mágicos e religiosos" (pp. 92, 94).

Ainda mais importante, era a "vocação missionária, a força que transformaria o Império sobretudo em um ato de fé" (p. 94). Em decorrência dessa fé, "o colono português estabeleceria com os povos exóticos relações, em geral, tolerantes e quase igualitárias; com eles aprenderia a lidar com ambientes inicialmente hostis, e a eles ensinaria a língua, a religião e a cultura 
de Portugal. Se este elemento já aparece em algumas das conferências do encontro de Alta Cultura Colonial e na Exposição do Mundo Português, é a partir da década de 50, com o luso-tropicalismo de Gilberto Freyre, que o Brasil ganhará grande proeminência com relação aos destinos do Império" (p.100).

E a Gilberto Freyre, Thomaz dedica a última seção do artigo. Pode-se concordar ou não com sua análise. Certamente seria preciso matizar a exposição aqui e ali. Ocorrem-me algumas questões que se poderia dirigir a esse pesquisador tão consciencioso no emprego de fontes originais. Até que ponto o discurso luso-tropicalista avant la lettre, das Conferências de Alta Cultura Colonial e de eventos análogos, é substancialmente diverso abstraindo-se peculiaridades de forma - do discurso das outras potências coloniais? O que terá de especificamente português em sua estrutura profunda? Que semelhanças e diferenças haveria entre o luso-tropicalismo (não necessariamente o de Gilberto Freyre) e o discurso da francité e da francophonie, com seus congressos, concursos, prêmios, chegando mesmo à eleição para a Académie Française o franco-tropical arquetípico, o presidente Léopold Senghor?

Outra questão diz respeito ao "diálogo implícito de Freyre com a intelectualidade colonialista das primeiras décadas do salazarismo" (p. 87), que impõe a Thomaz o dever de explicitar como se urdiram tais implicações. Eu vejo mal o Gilberto das décadas de 1930 e de 1940, deixando-se embeber pelo pensamento dos participantes das Conferências de Alta Cultura Colonial, mas estou pronto a vê-lo melhor se for confrontado com demonstração convincente da opinião contrária.

A contribuição seguinte é de Lourdes Martínez Echazábal: 'O culturalismo dos anos 30 no Brasil e na América Latina: deslocamento retórico ou mudança conceitual' (pp. 107-24). Tudo está dito no título, se se levar em conta que deslocamento e a mudança se referem a racismo. Mas isto representa, digamos assim, trabalho de Sísifo, por ser raça "um conceito fluido e transformante, embora historicamente específico, de modo que seu significado é fruto das teorias, interesses e discursos sociais da época em questão" (Goldberg parafraseando Goldberg, refere-se 1993, p. 73), à raçaqua cultura, qua classe, e qua nação". (p. 112). Deduz-se então, que não há maneira de escapar ao racismo. Na conclusão, entretanto, a autora se revela mais indulgente que nas premissas. "Considero que a suposta ruptura epistemológica que se cristaliza na década de 30 representa um deslocamento dentro do discurso da mestiçagem e não uma mudança de discurso. Este deslocamento, se bem que retórico, teve um impacto significativo (e) tem marcado e contribuído para mudar conceitualmente o discurso da identidade (cultural, nacional, regional) na América Latina até os dias atuais" (p. 121).

Ricardo Ventura Santos ocupa-se 'Da morfologia às moléculas, de raça à população: trajetórias conceituais em antropologia física no século XX' (pp. 125-40). Sua primeira tese é que não se deve mais falar em raça, só em "população", isto é, grupos "em isolamento reprodutivo, nem mais nem menos" (p. 137). A segunda mensagem é que, de acordo com os ensinamentos do neodarwinismo, "raça' (isto é - ou devia ser — população) foi sendo redefinida de modo a efetivar uma conciliação com um evolucionismo cuja ênfase era em dinamismo e mudança" (p. 129). E esse neodarwinismo, para Santos, em nada destoaria da tradição antropológica 
boasiana em matéria de antropologia física. $O$ artigo não se restringe a essas considerações teóricas. Trata também das "Declarações da Unesco: política, raça e população" com suas hesitações sobre se "os grupos humanos não diferem em suas características mentais inatas, seja inteligência ou comportamento" ou se, de maneira mais atenuada, "no tocante à inteligência, temperamento, cultura e 'raça' (...) os dados disponiveis não permitiam comprovar ou rechaçar a existência de associações" (pp. 129, 132).

Chegamos então à terceira parte do volume: 'O Brasil como 'laboratório racial': os estudos sobre as relações raciais entre os anos 40 e 60' (pp. 143-93). O primeiro artigo é de Antônio Sérgio Alfredo Guimarães e se intitula 'Cor, classe e status nos estudos de Pierson, Azevedo e Harris na Bahia: 1940-1960' (pp. 143-57). Donald Pierson, sociólogo norte-americano ligado à Universidade de Chicago, é autor de Brancos e pretos na Babia, livro publicado em 1945, com enorme sucesso até os dias de hoje, não obstante, suas teses só façam sentido "no contexto da sociologia americana da época" (p. 147). Conforme salienta Guimarães, para Pierson "na sociedade baiana e brasileira em geral não existiam castas raciais ou mesmo grupos raciais stricto sensu posto que brancos, pretos e mestiços eram encontráveis, de fato e em tese, ainda que em proporções diferentes, em todas as classes e grupos sociais.... O Brasil seria tipicamente uma sociedade multirracial de classes. ... Essa concepção ... opõe-se à ... de uma sociedade dividida ao mesmo tempo em classes e em castas raciais, tal como a sociedade sulista dos Estados Unidos caracterizada por Lloyd Warner" (p.149).

As idéias de Marvin Harris, por sua vez, são sumarizadas por Guimarães com rara felicidade. "No Brasil a discriminação de classe mostrou-se historicamente suficiente para manter os privilégios ... dos clominantes sem que esses precisassem apelar diretamente para uma estratégia étnico-racial. A construção social da raça teria se limitado, portanto, a um gradiente valorativo branco-preto onde o branco polarizaria os valores positivos, restando ao negro os valores negativos. Tal construção racial seria, portanto, capaz de gerar e alimentar preconceitos raciais, mas incapaz de sustentar discriminações sistemáticas pela simples ausência de regras objetivas de pertinência grupal à de descendência racial. Sem ser, pois, o paraíso racial que sugerem as idéias de Donald Pierson, o Brasil seria, ainda assim, uma sociedade onde as discriminações seriam propriamente de classe e não de raça" (p. 151).

As inovações de Harris com relação às idéias de Pierson seriam, ao menos em parte, devidas à influência de Thales de Azevedo. Mas a leitura deste autor é qualificada como "pobre", já "que não apreende a novidade teórica introduzida por ele" (p. 152). E qual seria esta novidade? "A inovação de Thales consiste justamente em teorizar a transição do Brasil colonial, arcaico, para um Brasil moderno, capitalista, em termos da passagem de uma sociedade de status para uma sociedade de classes, indicando como a associação entre status $e$ cor permanece incólume nessa transição" (p. 153). Qualquer semelhança com Florestan Fernandes não é mera coincidência: este, justamente, "irá desenvolver essas idéias embrionárias de Azevedo em algumas passagens auspiciosas de $A$ integração do negro na sociedade de classes... onde interpreta o 'preconceito de cor' como um resquício da sociedade escravocrata, cuja função na ordem capitalista seria deletéria. No período de transição para o capitalismo, o preconceito teria a única 
função de resguardar as distâncias de uma hierarquia estamental já superada em seus fundamentos econômicos." Segundo o autor do artigo, o tempo se encarregou de mostrar que as intuições de Azevedo estavam erradas: "a ordem capitalista, longe de prescindir do 'preconceito de cor', parece ter feito dele um dos seus principais mecanismos de reprodução de desigualdades sociais" (p. 155).

O artigo de Maria Lúcia de Santana Braga focaliza "Roger Bastide, paisagista" (pp. 159-78). Reunindo sociologia e arte, o antropólogo francês teria descrito nossa paisagem cultural e social, traçando um retrato poético do negro brasileiro. Com relação a Cruz e Souza, teria inclusive interpretado - asseguranos a autora - "o aparente paradoxo que é o de um descendente de africanos ter sido o maior representante da poesia simbolista no Brasil, visto que o simbolismo é essencialmente nórdico e apoiado na filosofia platônica". A vontade de negar as origens africanas e o sonho de ser ariano" (p. 163), que teriam inspirado a poesia de Cruz e Souza, são bem plausíveis, especialmente se nos lembrarmos que Calderón de la Barca, a seu modo também platônico, diz que "la vida es sueño". Não fica claro, entretanto, se, para Bastide, visto por Braga, tratavam-se de idéias fora de lugar ou de um negro fora de lugar.

Para o eminente franco-brasileiro, que, ficamos sabendo, participou do famoso Projeto Unesco, "o preconceito racial não se apresenta explicitamente, mas na ausência de um sistema de reciprocidade nas relações entre brancos e negros" (p. 165). A conclusão da autora é que "Bastide percebeu não somente o manifesto dos fenômenos, mas a essência da cultura brasileira... assim como Machado de Assis foi também um dos maiores paisagistas do Brasil" (p. 177).

O texto de Marcos Chor Maio, intitulado 'A questão racial no pensamento de Guerreiro Ramos' (pp. 179-93), é um dos principais do livro que organizou com Ventura dos Santos. Alguns dos conceitos-chave deste sociólogo aproximam-se dos de Donald Pierson, cujo "estudo publicado em português ... sobre ser uma análise lúcida e clara das relações de raça naquele estado [na Bahia], revelou-nos a riqueza da metodologia sociológica americana" ( $p$. 180). De modo que, para Guerreiro Ramos, "O preconceito com relação ao negro seria de cor e não de raça e ... não haveria uma linha de casta no Brasil" (p. 182). Ele apresenta outra peculiaridade com relação aos demais autores examinados na coletânia: opõe-se radicalmente à valorização de "sobrevivências africanas". E a tal ponto que foi autor da seguinte tese, rejeitada, em 1953, por um congresso de sociólogos (talvez temessem o desemprego, inclusive de antropólogos, que dela poderia resultar): "É francamente desaconselhável que o trabalho sociológico, direta ou indiretamente, contribua para a persistência, nas nações latino-americanas, de estilos de comportamento pré-letrado. Ao contrário, no que concerne às populações indígenas ou afro-americanas, os sociólogos devem aplicar-se no estudo e na proposição de mecanismos de integração social que apressem a incorporação desses contingentes humanos na atual estrutura econômica e social dos países latino-americanos" (p. 186).

Tendo em vista a prevalência daquilo que Joel Rufino dos Santos adiante, neste volume, chamará de 'povidade', sobre a simples 'negritude', não se pode deixar de concordar com o que afirma Maio nas linhas e, sobretudo, nas entrelinhas da conclusão: "Guerreiro apostou no fortalecimento de uma democracia substantiva inspirada no modelo nacional-desenvolvimentista 
cepalino. A sociologia de Guerreiro Ramos tem várias marcas do contexto histórico das décadas de 1940 e 1950 . No entanto, as reflexões e desafios elaborados pelo intelectual baiano ainda são de extrema atualidade" (p. 191).

Em apenas oito sucintas e densas páginas, Maria Arminda do Nascimento Arruda contribui com 'Dilemas do Brasil moderno: a questão racial na obra de Florestan Fernandes' (195-203). A análise se concentra no que é, sem dúvida, o principal trabalho de Florestan, $A$ integração do negro na sociedade de classes, publicado em 1965. Ouçamos a autora: (Florestan) "parte da desagregação da relação escravista, da formação de uma sociedade capitalista que se mescla a uma visão tradicionalista do mundo ... o autor centra o foco de análise na condição de marginalidade dos negros ante os novos padrões sociais inerentes à sociedade capitalista" (p. 196).

Acrescenta a autora, "a esse fenômeno de demora cultural, de persistência de relações arcaicas, corresponde a identidade negra não constituída" (p. 197). E tudo fica dito, ou antes, ficaria, se Florestan, com o tempo, não viesse a adotar o que certos metodólogos chamam de hipótese ad boc para explicar por que as coisas não aconteceram como previsto no figurino. É o que faz em Capitalismo dependente e classes sociais na América Latina, publicado sob o impacto do regime militar, em 1973. Citemos ainda a comentadora: "Às dificuldades internas da modernização acopla-se a ingerência externa, inibindo o pleno florescimento da ordem social competitiva e dissociando capitalismo e democracia. Daí a noção de capitalismo dependente, no qual o Estado passa a ser a espinha dorsal das transformações e a distribuição de poder migra da ordem social competitiva" (p. 202).

Chegamos desta maneira à última parte da obra coletiva, 'Perspectivas contemporâneas acerca da questão racial' (pp. 307-249), que, ainda que seja a mais atual, não deixa de ser a mais curta. O primeiro artigo é de uma estrela ascendente no céu da raciologia brasileira: Livio Sansone com 'As relações raciais em Casa-grande e senzala revisitadas à luz do processo de internacionalização e globalização' (pp. 207-17). O que o autor descreve, fundamentalmente, são os resultados de sua pesquisa em Salvador, Bahia. Sua principal conclusão é que "as relações raciais podem ser vistas como algo possível de ser decomposto em 'fatias'. ... As áreas 'duras' pela relação de cor são: 1) o trabalho e a procura do trabalho em particular; 2) o mercado matrimonial e da paquera e 3) os contatos com a polícia. ... Já as áreas 'moles' são todos aqueles espaços (nos quais) ser negro não dificulta e pode às vezes dar prestígio. Abrange o domínio do lazer, em particular o botequim, o dominó, o baba, o bate-papo com os vizinhos na esquina, o sambão, o carnaval, o São João ... a torcida, a seresta e naturalmente a própria turma grupo de 'iguais' com os quais se compartilha uma boa parte do lazer em público. Há também a Igreja Católica, os crentes e os círculos espíritas. Estes podem se considerados espaços negros implícitos, lugares nos quais ser negro não deveria ser obstáculo. Há também os espaços negros explícitos, os lugares nos quais ser negro pode ser uma vantagem: o bloco afro, a batucada, o terreiro de candomblé e a capoeira" (pp. 210-211). Ao leitor parecerá improvável, não obstante o que diz Sansone, que não ocorram paqueras supostamente pertencentes às "áreas duras" nos "domínios do lazer ... sambão, carnaval, São João".

Longe de derrubar as colunas do templo gilbertofreyriano, Sansone ajuda a sustentá-las, pois, "inspirando discursos, sonhos e, às vezes, práticas, o 
mito da democracia racial tem um componente de realidade, não podendo ser simplesmente apagado da análise antropológica como se fosse um disfarce imposto para mascarar uma realidade de racismo. ... Estes são aspectos freqüentemente descuidados pelo olhar 'lusófobo' (cujos representantes) parecem fascinados por uma hipotética polarização racial no Brasil. Não procurar entender o funcionamento destes segredos baianos no que tange às relações raciais ... pode significar descrever os negros brasileiros como uma massa de 'não assumidos' (o que, hoje, quase equivale a estúpidos) e as relações raciais como farsa ambígua e hipócrita" (p. 215).

Segue-se a curta e densa contribuição de Joel Rufino dos Santos, 'O negro como lugar' (pp. 219-23). O ponto de partida é que não há raças, uma vez que só existem "conjuntos de freqüências genéticas" (p. 219). Mas, acrescenta logo o autor, "Não há raças e entretanto há relações raciais. Paradoxo? Não, na realidade, a expressão 'relações raciais' acoberta outras relações, corresponde a um eufemismo. Racismo pode ser definido como ... relações de dominação disfarçadas sob a crença de que são raciais, isto é, de que há raças" (p.219). Do que deriva uma conseqüência importantíssima: "Os oponentes do racismo, a começar, no Brasil, pelos movimentos negros, valemse do conceito de raça e, por vezes, na sua versão oitocentista. São racialistas anti-racistas" (p. 219). Santos observa que "a democracia racial é, basicamente, o pacto nacional, supra-ideológico, de não considerar a interação racial como significativa. O movimento negro como tal é a ruptura desse pacto" ( $\mathrm{p}$. 220). Não se conclua, porém, que sugere, colocar classe no lugar de raça. $O$ que, ele sugere é a volta ao povo. "Ao invés de negritude, povidade. É possível que se fosse vivo hoje Guerreiro Ramos criticasse uma espécie de 'sociologia de resultados', de corte norte-americano, que se esmera sadicamente em medir o 'lugar do negro no mercado do trabalho', para chegar sempre à mesma conclusão, já dada no início, de que os negros ocupam os piores lugares e são os mais mal pagos dentre os brasileiros" ( $\mathrm{p}$. 222). Tal crítica tem endereço certo, e a ele haveremos de chegar antes do fim do volume.

Yvonne Maggie também comparece nesta autêntica enciclopédia dos estudos raciais brasileiros com o artigo: 'Aqueles a quem foi negada a cor do dia: as categorias cor e raça na cultura brasileira' (pp. 225-34). Sua abordagem é estritamente antropológica e estruturalista: "Sendo a lógica das classificações o próprio objeto da antropologia desde o seu nascimento, podemos dizer que os sistemas classificatórios, a partir dos quais são decalcados significados, marcam distinções no social. O que significa que as distinções não estão contidas na natureza das coisas ou dos seres. Na natureza tomam-se diferenças para construir, através das oposições binárias, distinções sociais fundamentais" (p. 226). O que, no caso das relações raciais, implica julgamentos de valor: "Claros e escuros referem-se também à cultura, porque, ao se referir a mais ou menos claros e mais ou menos escuros, aquele que classifica está fazendo um julgamento de valor" (p. 229).

Tudo então se explica com a varinha de condão do pensamento binário. Tudo menos o uso simultâneo ou alternado, em recenseamentos ou pesquisas de amostragem, de oposições e perguntas abertas, do tipo: "qual a cor do senhor?" e/ou "entre branca, preta, amarela e parda como classificaria a cor do senhor?". Mas tudo se concilia se pensarmos que "a hierarquia que constrói diferenças valorizando os mais claros e constrangendo os mais escuros não é 
senão um outro modo de expressar oposição" (p. 233). Maggie se pergunta por que Camões utilizou a metáfora "negar a cor do dia" em vez de "conceder a cor da noite", e conclui que "gradiente da hierarquia que se constrói por aproximação tem no moreno o seu ponto de maior síntese" (p. 233).

Finalmente, nos deparamos com o artigo de Carlos Hasenbalg, 'Relação entre o mito e os fatos: racismo e relações raciais no Brasil' (pp. 235-49). Como em tantos outros trabalhos deste, pode-se dizer, incansável apóstolo da denúncia das desigualdades raciais em nosso país, apresenta um conjunto de dados estatísticos arrasadores sobre as diferenças entre brancos e "não brancos". Mortalidade infantil, expectativa de vida, disparidades educacionais, renda etc. etc. Ao autor desta resenha não interessa nem sobra competência para fazer a crítica propriamente demográfica desses dados que, ao menos em parte, coincidem com as conclusões do senso comum de brasileiros de Norte a Sul. É o que tem sido também explicado, desde Pierson, como associação empírica entre "cor" e "classe". Boa parte dos estudos sobre raça, ciência e sociedade, no Brasil e no exterior, têm se voltado justamente para a compreensão dessas diferenças e, em certos casos, de sua persistência mesmo depois da implementação de programas de "ação afirmativa" ou equivalentes. Não basta, como assinalou com muita propriedade Joel Rufino dos Santos, entregar-se ao exercício sado-masoquista da repetição contínua das cifras. Há alguma explicação para esse estado de desigualdade? De acordo com o paradigma sugerido por Hasenbalg, desde, pelo menos, 1979, a desigualdade seria decorrência de mecanismos de discriminação que jamais explicita, jamais operacionaliza, nem transforma em hipóteses testáveis ou, como diria Popper, "falseáveis". A hipótese da discriminação, como sugere mas não verifica Hasenbalg, vem a ser então uma hipótese "metafísica".

Terminada a leitura do volume, concluímos que os organizadores atingiram plenamente o tríplice objetivo da apresentação diacrônica, de uma certa interdisciplinaridade e, last but not least, dos subsídios para a compreensão do cenário contemporâneo ou, pelo menos, do que se pensa sobre esse cenário em alguns dos círculos intelectuais mais distintos do país. As contribuições são desiguais e nem sempre as mais longas são as mais densas e pertinentes. Há omissões a lamentar. Nada há de específico sobre Gilberto Freye, o grande presente-ausente com que todos, ou quase todos, parecem querer dialogar ou refutar, nem sobre Jorge Amado, o partido ou os partidos comunistas, o movimento integralista etc. Mesmo com tais omissões e, talvez, uma ou outra presença ou desenvolvimento supérfluo, Raça, ciência e sociedade constitui efetivamente quase que uma enciclopédia dos estudos raciológicos no Brasil, além de representar documentação de primeira ordem para o estudo de como nosso momento histórico vê a si mesmo e como interpreta corrrentes passadas que, ao contrário do que sugere o provérbio, continuam a mover moinhos. 